\title{
MENINGKATKAN KINERJA: INTERNAL \& EXTERNAL FACTORS
}

\author{
Ade Suherlan \\ UIN Syarif Hidayatullah, Jakarta \\ suherlanade@gmail.com
}

Submitted: $15^{\text {th }}$ August $2019 /$ Edited: $06^{\text {th }}$ November $2019 /$ Issued: $01^{\text {st }}$ January 2020

Cited on: Suherlan, Ade. (2020). MENINGKATKAN KINERJA: INTERNAL \& EXTERNAL FACTORS. SCIENTIFIC JOURNAL OF REFLECTION: Economic, Accounting, Management and Business, 3(1), 1-10.

DOI: $10.37481 /$ sjr.v3i1.110

https://doi.org/10.37481/sjr.v3i1.110

\begin{abstract}
Providing excellent service is mandatory, the customer feels the warmth of the employee, hospitality, smile, responsiveness, and tenderness. The company must work hard, encourage performance improvement, commitment, stimulate self-enthusiasm by promoting career development. This research is intended to look at internal and external performance factors. The reason for using quantitative methods is simple, and can show clarity of interpretation. To collect data, questionnaires were distributed. Respondents answered according to predetermined criteria (Likert scale), then the data were analyzed using regression. The results of the study confirm that performance can develop significantly if internal and external factors are built up. In the long term career strategies are needed, but in operational (daily) efficacy and commitment are needed.
\end{abstract}

\section{Keywords : Performance, Efficacy, Commitment, Career Development}

\section{PENDAHULUAN}

Tidak banyak pilihan di era modern kecuali meningkatkan kemampuan dan kinerja, sehingga dalam kondisi ini akan membutuhkan sumber daya manusia (human resources) yang berkualitas yang dapat menjalankan organisasi. Sumber daya manusia (human resources) yang berkualitas merupakan aset bagi organisasi karena perannya sebagai pelaksana kebijakan dan yang dapat menjalankan kegiatan operasional organisasi tersebut. Oleh karena itu dalam mencapai tujuan organisasi dibutuhkan peran sumber daya manusia (human resources) yang memadai dalam mendorong kinerja dan sehingga dapat berkompetisi dengan organisasi lainnya. Hal ini di dukung oleh Perez \& Pablos (2003), bahwa sumber daya manusia merupakan kunci untuk mencapai keunggulan kompetitif. Tung (2008), persaingan bukan untuk dihindari namun segera 
mempersiapkan apa yang dimiliki khususnya tenaga kerja, mereka adalah kunci memenangkan persaingan.

Salah satu ukuran SDM unggul dapat dilihat dari tingkat kinerjanya. Menurut Yussof \& Ismail (2002) ketergantungan perusahaan terhadap kinerja pegawai seperti gula dan semut, keduanya saling memberikan manfaat. Akan tetapi, penekanan kinerja terfokus pada apa yang harus ditampilkan oleh pegawai, baik berupa hasil maupun kreativitas, dan kesemuanya dipengaruhi oleh banyak faktor. Ordonez de Pablos (2005) menjelaskan tidak cukup hanya dengan memberikan satu kebaikan, kinerja itu kompleks, terdiri dari berbagai elemen bahkan emosi, maka sekalipun itu kompensasi yang tinggi belum tentu menghasilkan kinerja yang maksimal, perusahaan harus memberikan semua yang dimiliki tanpa terkecuali.

Sejalan dengan penjelasan di atas, bank DKI fokus pada upaya peningkatan kinerja pelayanan, sehingga para nasabah tetap terjaga. Hasil wawancara dengan salah satu pegawai bank DKI, menuturkan pelayanan adalah prioritas, maka seluruh upaya harus dikerahkan guna memberikan kepuasan nasabah. Beberapa faktor yang dapat dikembangkan agar meningkatnya kinerja pegawai seperti: perusahaan memotivasi pegawai agar melahirkan efikasi diri yang matang sehingga pegawai dapat bekerja penuh percaya diri, perusahaan mendorong agar pegawai meningkatkan komitmennya dan memberikan daya tarik bagi pegawai untuk bekerja dengan baik yakni dengan mengembangkan program pengembangan karier yang terbuka untuk semua pegawai.

Lebih lanjut dikemukakan, dalam rangka pemenuhan kebutuhan dan kepuasan nasabah maka perbaikan pelayanan yang prima tidak ada hentinya untuk terus ditingkatkan apalagi di zaman sekarang yang menuntut serba cepat, sederhana dan mudah. Oleh karena itu, kepercayaan kerja dan keyakinan diri dari para pegawai untuk saat ini belum dapat dikatakan maksimal, perlu terus didorong dan diarahkan agar totalitas bekerja dalam melayani nasabah tidak ragu-ragu atau setengah-setengah, akan tetapi semua pegawai dengan keyakinan yang tinggi dapat membantu kebutuhan, keinginan dan menyelesaikan permasalahan nasabah terkait jasa keuangan.

Seiring penjelasan di atas ternyata kondisi di lapangan (pegawai Bank DKI Pusat) dirasa masih belum optimal. Berdasarkan hasil wawancara dengan salah satu pegawainya mengungkapkan komitmen pegawai saat ini masih belum maksimal. Salah satu faktor yang melatar belakangi adalah kurangnya kesadaran dalam diri pegawai 
tersebut serta dari pihak perusahaan masih jarang menerapkan program pengembangan sebagai pendorong semangat pegawainya serta kuatnya tekanan kerja yang menuntut pegawai harus bekerja dengan keras dan mampu menangani banyak pekerjaan.

Berdasarkan hasil wawancara dengan salah satu pegawai bank DKI pusat, beliau menuturkan pengembangan karier di dunia perbankan khususnya bank DKI ini meskipun terbuka luas tapi sangat sulit untuk dicapai. Jenjang karier harus dicapai dengan kerja keras ditambah harus terpenuhinya syarat administrasi promosi serta butuh waktu masa kerja yang cukup lama agar memperoleh promosi jabatan. Hal tersebutlah yang sering kali menjadi faktor berat bagi para pegawai ditambah kerja di dunia perbankan tekanan kerja sangat tinggi, di mana pegawai dituntut kerja dengan kualitas yang baik, cepat dan prima.

\section{LANDASAN TEORI}

Efikasi diri dianggap penting dalam mendorong lahirnya kinerja pegawai, karena hubungannya dengan kehidupan dalam suatu organisasi yang di dalamnya dibutuhkan kepercayaan diri dan keyakinan yang mantap dari pegawai itu sendiri (Chyung, 2007; Hmieleski \& Corbett, 2008). Efikasi diri menurut Moores \& Chang (2009) mengungkapkan bahwa kinerja pegawai dapat lahir dengan maksimal apabila para pegawai memiliki rasa percaya diri dan keyakinan kerja yang juga akan mempengaruhi tingkah laku kerja yang positif. Artinya perilaku anggota organisasi baik secara individu maupun kelompok memberikan kekuatan atas kinerjanya melalui keyakinan kerja yang. Keyakinan inilah yang disebut efikasi diri (self efficacy). Chang, et al (2014), apakah perusahaan dapat memberikan garansi tentang masa depan pegawai, tentu tidak. Namun sejak hari pertama seseorang bekerja, ia telah membawa keyakinan dan kepercayaan bahwa dirinya harus berguna bagi organisasi, maka seiring waktu ia tumbuh dan membesarkan perusahaan.

Faktor lain yang dapat mempengaruhi kinerja pegawai adalah komitmen pegawai (Ahmad, dkk 2010). Komitmen itu sikap baik yang harus dipelihara, dan jelas berpengaruh terhadap totalitas di dalam bekerja (Salleh, et al., 2013; Susanty, et al., 2013; Sheu \& Hu, 2009). Selain itu komitmen pegawai diartikan sebagai konsep yang memandang pengabdian atau dedikasi terhadap pekerjaan sebagai nilai yang sangat berharga (Ashill, et al., 2008; Iun \& Huang, 2007; Sawitri, et al., 2016). Artinya 
komitmen menegaskan keberpihakan pegawai terhadap tujuan organisasi. Dengan kata lain, jika sebuah komitmen sudah dibangun dengan baik antara pegawai dengan perusahaan maka akan berdampak pada sebuah kesepakatan yang saling menguntungkan, di mana pegawai akan bekerja penuh semangat dan menghantarkan pencapaian prestasi perusahaan dan perusahaan memberikan kecukupan kebutuhan pada pegawai baik moril maupun materil.

Penjelasan di atas memberikan kesimpulan arti bahwa pegawai yang memiliki komitmen yang baik, mereka akan mendedikasikan dirinya terhadap organisasi di mana ia bekerja dengan bekerja tekun, ulet, penuh semangat, berorientasi pada hasil yang baik dan meningkatkan produktivitas kerja. Selain itu komitmen juga menjadikan pegawai loyal dan merasa memiliki pada organisasinya sehingga setiap kali ia bekerja maka orientasinya adalah bagaimana bekerja dengan baik kemudian menghasilkan pekerjaan yang sesuai, sehingga dapat memberikan prestasi kerja yang tinggi dan menghantarkan organisasi pada pencapaian tujuannya. Sebagaimana hasil penelitian yang dilakukan oleh Folorunso, et al. (2014) bahwa komitmen mengarahkan orang pada pekerjaan yang dilakukan dengan sungguh-sungguh dan berorientasi pada hasil yang memuaskan. Hal ini mengindikasikan bahwa komitmen memiliki korelasi yang positif terhadap peningkatan kinerja.

Selanjutnya dalam upaya peningkatan kinerja pegawai maka faktor pengembangan karier memiliki pengaruh yang cukup penting. Menurut Dvir, et al. (2002 menyatakan bahwa pengembangan karier mempunyai relevansi langsung bagi kepuasan anggota organisasi. Itu artinya ketika pegawai merasa terpuaskan mereka akan melakukan yang terbaik untuk meningkatkan kinerjanya, karena mereka merasa senang berada di organisasi tersebut dengan adanya pengembangan karier yang jelas.

Sedangkan menurut Nadarajah, et al. (2012 pengembangan karier adalah bentuk penghargaan atas sejumlah pengabdian, prestasi dan dedikasinya terhadap organisasi. Selain itu pengembangan karier adalah salah satu upaya yang harus dilakukan oleh organisasi untuk mengelola dan mengembangkannya sehingga dapat mendorong pegawai untuk lebih produktif. Hal ini didukung oleh pernyataan Sofyan, dkk. (2016) yang mengemukakan bahwa adanya pengembangan karier akan mendukung efektivitas individu dan organisasi dalam mencapai tujuan organisasi. Dengan memberikan perhatian terhadap karier yang diinginkan para pegawai, maka senantiasa mereka akan 
meningkatkan komitmen mereka pada organisasi sehingga mendorong peningkatan kinerjanya. Selain itu, pengembangan karier akan mendorong seseorang untuk lebih termotivasi di dalam meningkatkan prestasi kerjanya (Van der Heijden, et al., 2009).

\section{METODE PENELITIAN}

Hal-hal ilmiah diperlukan seperti metode penelitian kuantitatif. Metode ini banyak digunakan karena hasilnya mudah dijelaskan dan ada banyak eksplanasi yang dapat dikait-kaitkan, oleh karena itu penelitian ini menggunakan kuantitatif. Degradasi dari penelitian ini di tahap implementasi adalah survey berbasis wawancara atau kuesioner. Hal tersebut dilakukan karena dua alasan. Pertama, memberikan kemudahan bagi peneliti. Kedua lebih efektif dalam hal waktu dan kenyamanan responden.

Cara simple random diambil karena kesederhanaan kriteria. Sehingga penelitian hanya perlu fokus pada maksud jawaban responden tanpa mengakalinya. Akan tetapi agar ukuran tetap terjaga digunakan suatu skala liker, di mana pernyataan terkunci oleh suatu pilihan formal. Analisis regresi linear berganda dipilih untuk membuktikan hasil secara statistik.

\section{HASIL PENELITIAN}

Output statistik menunjukkan, efikasi diri berpengaruh terhadap kinerja pegawai dengan penjelasan sebagai berikut:

1. Persepsi pegawai terhadap efikasi adalah baik. Artinya, pegawai menganggap sebagai pekerja sudah seharusnya memiliki motivasi dan keyakinan. Sebab jika tidak, maka hanya akan membuat sulit pegawai di masa mendatang. Misalnya, bekerja kurang sesuai SOP, tidak mencapai target, mendapatkan hukuman, mendapatkan teguran, dll. Fakta-fakta tersebut yang membayangi pegawai untuk terus meningkatkan efikasi diri, terlepas dihargai atau tidak, diperhatikan oleh pimpinan atau tidak, diberikan kesempatan untuk berkembang atau tidak, atau lain sebagainya, keyakinan dalam bekerja harus ada, semangat kerja dipupuk, optimistis harus dipelihara, dan harapan harus digapai.

2. Signifikansi efikasi diri terhadap kinerja sebesar 0,438. Nilai kemungkinan tersebut menegaskan, bahwa kinerja tidak terlepas oleh faktor individu. Benar jika pegawai bekerja tidak hanya menggunakan kompetensi dan integritas. Keduanya 
adalah faktor yang akan maksimal jika pegawai memantapkan hati dan membulatkan tekad untuk bekerja dengan sungguh-sungguh. Maka kompetensi akan lahir, maka integritas akan terjaga, maka profesionalitas akan dihadirkan, maka inovasi akan dilahirkan, dll. Chang, et al. (2014) mengatakan, perusahaan tidak perlu risau terhadap kinerja pegawai yang memiliki kepercayaan, mereka jauh lebih memahami peran dan fungsinya, jika mereka gagal dengan sendirinya mereka akan mempertanggung jawabkannya.

Selain itu, peran komitmen terhadap kinerja dari hasil perhitungan SPSS dapat dijelaskan sebagai berikut.

1. Pegawai menanggapi soal komitmen cukup tinggi. Bahwa dalam dunia layanan keuangan pelayanan adalah nomor satu, karena hal tersebut menyangkut kepercayaan nasabah. Adapun yang dimaksud pelayanan adalah komitmen seluruh pihak-pihak bank khususnya pegawai, berusaha menjalankan nilai-nilai kerja yang telah ditetapkan yakni; 1) menjadi pegawai yang jujur di dalam menyampaikan informasi (lengkap dan akurat). 2) melayani dengan hati, sepenuh hati, dan hati-hati. 3) berperilaku baik, benar, dan taat pada aturan. 4) menjunjung integritas dan moralitas. dan 5) menghindari perilaku yang dapat merugikan perusahaan dan nasabah.

2. Nilai regresi sebesar 0,386. Artinya, komitmen dapat mempengaruhi kinerja dengan arah yang positif. Jika tekad telah bulat dan berubah menjadi suatu sikap serta tindakan maka pegawai di dalam kesehariannya akan bekerja penuh prestasi. Bahwa kesehariannya tidak lain adalah bekerja dengan baik dan penuh target, ia berusaha bekerja lebih keras dari yang lain agar membuktikan apa yang seharusnya ia lakukan, ia mempengaruhi lingkungan dengan memberikan contoh perilaku kerja yang gemilang. Ahmad, dkk (2010), komitmen itu sikap yang letaknya ada di hati dan pikiran pegawai, namun jika pikiran telah sejalan dengan hati maka bukan saja bekerja secara profesional, melainkan bekerja sebagai ahli atau pakar, yang selalu punya cara menyelesaikan tugas lebih baik, yang selalu mengejutkan dengan memberikan ide-ide atau kreativitas, yang menjadi harapan dalam penyelesaian masalah. Dengan kata lain, komitmen tidak hanya berorientasi pada target, namun dampak dapat menyelesaikan hal-hal kecil lain yang masih berkaitan. 
Hal yang tidak kalah penting dari efikasi dan komitmen adalah pengembangan karier. Hasil olah data menunjukkan pengaruhnya signifikan terhadap kinerja sebesar 0,177. Adapun penjelasan rinci dapat dikemukakan sebagai berikut:

1. Indikator pengembangan karier yang dipersepsikan tinggi adalah kesempatan. Para pegawai melihat kesempatan adalah harapan yang tidak ada salahnya dicoba dan diupayakan untuk digapai, jika pada akhirnya tidak tercapai maka tidak ada salahnya.

2. Indikator pengembanan karier yang dipersepsikan kurang adalah promosi jabatan. Hal tersebut ditanggapi cukup sederhana, bahwa posisi pimpinan itu sedikit, maka tidak terlalu berharap pada hal tersebut adalah realistis. Melakukan pekerjaan dengan sungguh-sungguh adalah kewajiban, soal kelak diangkat menjadi pimpinan atau tidak itu soal takdir. Namun tetap saja, di hati kecil berharap, semoga di masa-masa mendatang dapat menjadi pimpinan, walaupun supervisor.

3. Nilai regresi 0,177 . Artinya pengembangan karier punya peran, meskipun tidak sebesar efikasi diri. Hal tersebut sebagai bagian realistis. Pertama, kinerja itu persoalan kewajiban maka sudah sepatutnya tugas diakukan dengan sebaikbaiknya tanpa melihat pada karier. Kedua, dalam pelaksanaan tugas pegawai tidak memikirkan karier sebagai motivasi utama, melainkan kehendak diri yang dominan/ semangat kerja dan komitmen. Dengan kedua hal tersebut, dapat dikemukakan karier berpengaruh sebagai suatu persepsi individu yang muncul pada saat-saat tertentu sehingga membangkitkan semangat di dalam bekerja.

Penjelasan di atas menegaskan, kinerja merupakan persoalan pegawai dan perusahaan. Bagi perusahaan, kinerja merepresentatifkan tercapainya keuntungan, kemajuan, tujuan, dan pangsa pasar. Sedangkan bagi pegawai kinerja adalah kewajiban yang berdampak baik pada kualitas hidup (dalam hal materil). Dengan kinerja pegawai mendapatkan hal yang diinginkan, bahkan diberikan penghargaan yang tinggi oleh lingkungan sekitar, kinerja pula dapat menghantarkan pegawai menjadi pimpinan di masa mendatang. Namun hal tersebut hanya akan terjadi bila kesiapan jiwa (efikasi diri) telah matang, menjaga komitmen untuk terus maju, melihat karier sebagai peluang yang memotivasi, mengasah diri dengan pengalaman, menempa kompetensi dengan belajar, melihat hal-hal baik sebagai tujuan, dan lain sebagainya. Hmieleski \& Corbett (2008) mengatakan, kinerja bukan sekedar kewajiban, akan tetapi sebuah kerja keras yang 
dilandasi kebanggaan, kepercayaan, moral, dan semuanya dibalut oleh kebahagiaan dan kepuasan, maka pegawai pantas untuk puas dengan semua itu.

\section{KESIMPULAN}

Kesimpulan yang cukup mengejutkan, bahwa kinerja lebih dekat dengan efikasi diri di bandingkan komitmen dan pengembangan karier. Fakta ini menjelaskan bahwa pegawai bank memiliki emosionalitas yang kuat sehingga dapat mempengaruhi keseluruhan perilaku kerja. Namun, peran komitmen terlihat berarti ketika kinerja hendak dijaga, dalam hal ini konsistensi capaian. Seorang pegawai bank akan berusaha keras untuk mendapatkan penilaian baik dari nasabah, dan ia tidak akan menyianyiakan apa yang telah dicapai dengan berusaha menjadi pribadi yang lebih baik.

Sedangkan pengembangan karier yang dimaksud adalah suatu perencanaan karier. Peran program pengembangan karier sangat baik bagi motivasi pegawai. Mereka jadi memiliki banyak tujuan di dalam organisasi, sehingga pola kerja menjadi tidak monoton, karena selalu ada yang harus dicapai. Selain itu juga, program pengembangan karier cukup baik dalam memelihara semangat menjaga kinerja di masa-masa mendatang.

Temuan dari penelitian ini, secara tidak langsung membuka fakta bahwa keberlangsungan organisasi ada di tangan pegawai. Namun pegawai yang dimaksud adalah mereka yang mampu berkinerja, dan untuk mencapai hal tersebut pegawai harus dikembangkan, dibina, dilatih, dan diberdayakan sehingga lahir jiwa pekerja sejati yang penuh semangat dan menyemangati orang lain, yang berkomitmen dan berani bertanggung jawab, yang orientasinya target dan prestasi demi menggapai karier yang diimpikan.

\section{DAFTAR PUSTAKA}

Ahmad, H., Ahmad, K., \& Shah, I. A. (2010). Relationship between job satisfaction, job performance attitude towards work and organizational commitment. European journal of social sciences, 18(2), 257-267.

Ashill, N. J., Rod, M., \& Carruthers, J. (2008). The effect of management commitment to service quality on frontline employees' job attitudes, turnover intentions and service recovery performance in a new public management context. Journal of Strategic Marketing, 16(5), 437-462. 
Chang, C. S., Liu, E. Z. F., Sung, H. Y., Lin, C. H., Chen, N. S., \& Cheng, S. S. (2014). Effects of online college student's Internet self-efficacy on learning motivation and performance. Innovations in education and teaching international, 51(4), 366-377.

Chyung, S. Y. Y. (2007). Age and gender differences in online behavior, self-efficacy, and academic performance. Quarterly Review of Distance Education, 8(3).

Dvir, T., Eden, D., Avolio, B. J., \& Shamir, B. (2002). Impact of transformational leadership on follower development and performance: A field experiment. Academy of management journal, 45(4), 735-744.

Folorunso, O. O., Adewale, A. J., \& Abodunde, S. M. (2014). Exploring the effect of organizational commitment dimensions on employees performance: An empirical evidence from Academic Staff of Oyo State Owned Tertiary Institutions, Nigeria. International Journal of Academic Research in Business and Social Sciences, 4(8), 275.

Hmieleski, K. M., \& Corbett, A. C. (2008). The contrasting interaction effects of improvisational behavior with entrepreneurial self-efficacy on new venture performance and entrepreneur work satisfaction. Journal of business venturing, 23(4), 482-496.

Iun, J., \& Huang, X. (2007). How to motivate your older employees to excel? The impact of commitment on older employees' performance in the hospitality industry. International Journal of Hospitality Management, 26(4), 793-806.

Moores, T. T., \& Chang, J. C. J. (2009). Self-efficacy, overconfidence, and the negative effect on subsequent performance: A field study. Information \& Management, 46(2), 69-76.

Nadarajah, S., Kadiresan, V., Kumar, R., Kamil, N. N. A., \& Yusoff, Y. M. (2012). The relationship of $\mathrm{HR}$ practices and job performance of academicians towards career development in Malaysian private higher institutions. Procedia-Social and Behavioral Sciences, 57, 102-118.

Ordonez de Pablos, P. (2005). Strategic human resource management and organisational competitiveness: the importance of fit and flexibility. International Journal of Human Resources Development and Management, 5(1), 1-15.

Perez, J. R., \& Pablos, P. O. D. (2003). Knowledge management and organizational competitiveness: a framework for human capital analysis. Journal of knowledge management, 7(3), 82-91.

Salleh, M., Amin, A., Muda, S., \& Halim, M. A. S. A. (2013). Fairness of performance appraisal and organizational commitment. Asian Social Science, 9(2), 121.

Sawitri, D., Suswati, E., \& Huda, K. (2016). The Impact Of Job Satisfaction, Organization Commitment, Organization Citizenship Behavior (Ocb) On Employees'performance. International Journal of Organizational Innovation, 9(2). 
Sheu, J. B., \& Hu, T. L. (2009). Channel power, commitment and performance toward sustainable channel relationship. Industrial Marketing Management, 38(1), 17-31.

Sofyan, M., Rahman, A., Bima, M. J., \& Nujum, S. (2016). The Effect Of Career Development And Working Discipline Towards Working Satisfaction And Employee Performance In The Regional Office Of Ministry Of Religious Affairs In South Sulawesi. International Journal Of Scientific \& Technology Research, 5(03), 51-57.

Susanty, A., Miradipta, R., \& Jie, F. (2013). Analysis of the effect of attitude toward works, organizational commitment, and job satisfaction, on employee's job performance. European Journal of Business and Social Sciences, 1(10), 15-24.

Tung, R. L. (2008). Brain circulation, diaspora, and international competitiveness. European Management Journal, 26(5), 298-304.

Van der Heijden, J. A., van Engen, M. L., \& Paauwe, J. (2009). Expatriate career support: Predicting expatriate turnover and performance. The international journal of human resource management, 20(4), 831-845.

Yussof, I., \& Ismail, R. (2002). Human resource competitiveness and inflow of foreign direct investment to the ASEAN region. Asia-Pacific Development Journal, 9(1), 89-107. 